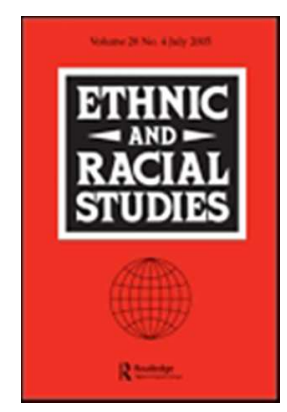

\title{
Unsettling intersectional identities: Historicising embodied boundaries and border crossings
}

\begin{tabular}{|r|l|}
\hline Journal: & Ethnic and Racial Studies \\
\hline Manuscript ID & RERS-2016-0597 \\
\hline Manuscript Type: & ERS REVIEW - BOOK SYMPOSIUM \\
\hline Keywords: & a, b, c, d, e, f \\
\hline \multicolumn{2}{l}{} \\
\hline
\end{tabular}

SCHOLARONE ${ }^{\text {IN }}$

Manuscripts 


\title{
Unsettling intersectional identities: Historicising embodied boundaries and border crossings
}

Ann Phoenix ${ }^{1}$

Thomas Coram Research Unit, Department of Social Science, UCL Institute of Education, London, UK

Helsinki Collegium for Advanced Studies, University of Helsinki, Helsinki, Finland

\begin{abstract}
At a time when the pace of global change has led to unprecedented shifts in, and unsettling of, identities, Brubaker brings 'trans/gender' and 'trans/racial' creatively into conversation to theorise the historical location of identity claims and to examine the question of whether identities are optional, self-consciously chosen and subject to political claims rather than biologically pre-given. His main argument is that the distinction between sex and gender allows us to construct gender identity as personal, individual and separate from the (biologically) sexed body. In contrast, other people always have a stake in allowing or challenging identity claims to racial identity. Brubaker's argument is persuasive. However, he treats both race and sex/gender as solipsistic and neglects the wider social context that has produced the conditions of possibility for the entrenched differences he records. An intersectional approach would have deepened his discussion of the place of categories in 'trans' arguments.
\end{abstract}

Keywords: historical location; identities; intersectionality; performativity; race; sex/gender; structural context

The plethora of publications on identity have produced a number of commonplaces about how to theorise it. These include notions that identities are multiple and in constant flux; that 'insider' understandings do not necessarily accord with 'outsider' constructions and that there are differences between people within any social identity category as well as commonalities across groups constructed as different (Foresight, 2013; Wetherell, 2009). At a time when there is also general agreement that the pace of global change has led to unprecedented shifts in, and unsettling of, identities, questions of what leads to change in identities, for whom and why is less clear. The centrality of these questions to Brubaker's new book makes it an inviting read for anyone interested in identities and particularly, gender, race and intersectionality. The main heading 'trans' adds intrigue as well as timeliness.

As with many academic publications, this text had an unexpected genesis. In spring 2015, Brubaker's attention was caught by two US news stories that generated 'vernacular' sociological debate in the media, including the blogosphere and social media. Briefly, Caitlyn Jenner, a former male Olympic gold medal decathlete and a member of the media-savvy Kardashian family, gained public support and acclamation when she made public her transition from male to female. The following week, Rachel Dolezal, then president of a chapter of the NAACP (National Association for the Advancement of Colored People, Spokane branch, USA) was reported to be white, rather than black, as she had claimed. Her parents' affirmation that she was definitely not black, led to her resignation from the leadership of the Spokane NAACP chapter and much public vilification on the grounds that it is not possible to change one's race. Dolezal's claim that she identifies as black was largely dismissed, while Jenner's identification as a woman was generally supported. Indeed, transgender and plural sexualities have rapidly gained legislative purchase in the US and many other countries after centuries of being undeclared, while changing race is no longer officially sanctioned in most countries.

\footnotetext{
${ }^{1}$ Email: a.phoenix@ioe.ac.uk
} 
The temporal juxtaposition of the two stories led to gendered/racialized comparisons that germinated Brubaker's desire to explore the 'unsettled identities' of gender and race. Brubaker calls his book an essay, not a monograph, because it is 'exploratory, tentative, and incomplete', trying-out new ideas. The resulting short book is a thought experiment that constitutes a nuanced consideration of similarities and differences in these two identity categories. It is undoubtedly a highly scholarly, well-referenced book, accessibly written with an admirably light touch. Brubaker goes beyond the syllogisms that characterized the public debate, which asked the question 'If transgender is acceptable, is transracial also acceptable and recognizable?' Instead, he treats the two events as an intellectual opportunity to 'think with trans', rather than about trans. He is not interested in lived experience, but 'contemporary transformations of, and struggles, over, gender and race as systems of social classification' (p.xi). In thinking 'with' Brubaker distinguishes conceptually the trans of 'migration' (moving from one to another category), 'between' (defining self in relation to existing binaries, but as different) and beyond (e.g. transcending categorization).

Bringing transgender and transracial creatively into conversation allows Brubaker to recognize the historical location of identity claims and to examine a range of questions that are central to current social science puzzles. For example, a key feature of the book is whether identities are optional to the extent that they have become the focus of self-conscious choices and political claims rather than being biologically pregiven. Brubaker also explores how the boundaries between categories is controlled and policed, as well as how new categories come into being. In addressing these issues, he lays out current thinking and contestations about the fluidity/fixity and contingency/essentialism of different kinds of identities. The simultaneous examination of transgender and transracial allows Brubaker to analyse the discourses of 'essentialists', 'voluntarists' and those who combine voluntarism with essentialism.

Methodologically, this book helpfully shows the utility of conducting thought experiments, in this case of bringing together concepts that are everyday and that are much debated by both public and academics. In examining processes of change in two major social categories, gender and race, Brubaker illustrates how each can enable consequential sociological analysis of the other and so add to social analysis.

Brubaker's main argument is that the tension between choice and 'givenness' plays out differently for sex/gender in comparison with race because, while both are becoming increasingly unsettled, the distinction between sex and gender allows us to construct gender identity as personal, individual and separate from the (biologically) sexed body. Brubaker refers to this as the 'objectivity of the subjective identity' (p. 7). As a result, only individuals themselves can claim knowledge of their gender identification, even though transgender people may be asked to prove their commitment to their identification before being granted access to medical interventions. 'The sex-gender distinction thus allows gender identity to be both disembodied and re-embodied' (p.137). In the absence of a comparable separation in racialization, there is no easy way to stake a claim to identification as black in the absence of phenotypical evidence and/or demonstrable black ancestry. In Brubaker's terms, 'subjectivity is understood as an expression of racial identity, not as its ground' (p. 37). As Brubaker points out, the inheritance of sex is not dependent on family history. Thus, while sex/gender are more fundamental and biologically consequential categories than racialized categories, other people always have a stake in allowing or challenging identity claims to racial identity in a way that they do not for claims to gender identities. Thus, 'our conceptual and linguistic resources for thinking about race make it nearly impossible to imagine racial identity in a similar way to gender identity' (p.137). 'Passing' for white or black is understood as inauthentic and dissimulation by getting others to 'misperceive' one's race and, in the case of the 'reverse passing' of which Rachel Dolezal was accused, of dishonestly appropriating a culture, history and social position. It is for these reasons, Brubaker suggests, that as projects of self-transformation, transgender and transracial produce different results despite their apparent similarities, with transgender being viewed as more transgressive and having disruptive potential. 
This might seem surprising given that there have been enormous changes in racialized demography in the US (as well as in other countries in the Minority world). In particular, there have been marked increases in 'mixed' relationships and children born to parents from different racialized and ethnicised groups as well as demands for 'multiracial' categories to be recognized. However, as Brubaker suggests, the persistent influence of the 'one-drop rule' continues to limit choices for racialized identities. Thus, while Brubaker points out that some feminists strive to restrict access to women's spaces to 'women-born women', he suggests that access to blackness is now more closely policed (unlike in the periods of slavery and 'Jim Crow' laws). Both instances of policing are unidirectional in that transgender men's access to male spaces is not policed in the same way and access to whiteness is not similarly policed. Brubaker suggests that the policing of migration is connected to concerns about cultural appropriation (for race) and access to spaces reserved for black people or women.

Brubaker's argument is persuasive, that sex/gender and race have different logics and moral orders. However, this is a partial explanation in that it treats both race and sex/gender as solipsistic and neglects the wider social context that has produced the conditions of possibility for the entrenched differences he records. He therefore takes too voluntaristic or optional a view of identity choices for gender. Yet, Brubaker recognizes that the world is 'crisscrossed by dense classificatory grids' (p.5) and briefly discusses intersectionality and its use to critique analogical reasoning of the kind invoked in comparisons of Caitlyn Jenner and Rachel Dolezal (p. 11). He recognizes that categories are internally differentiated and mutually constituted, but since he does not employ intersectional analysis, his essay does not sufficiently engage with differences within racialized and gendered categories or their simultaneity. What, for example, of transgender black people? What of white ones? An intersectional approach would also have buttressed his arguments for how categories are treated in 'trans' arguments since, for example, notions of going beyond race and gender categories have been much discussed in intersectional work following Leslie McCall's (2005) delineation of inter-, intra- and anti-categorical intersectional approaches.

Brubaker also downplays (although he does mention) the structural context that facilitates or constrains identity claims and how they are received by different others. This makes some of Brubaker's conclusions too simplistic. For example, he describes the 'performative turn' as interlinked with identities and structures, but focuses attention on the identity element, rather than the structural. Yet, they are inextricably linked. Butler (1990: 25) introduced performativity as more than reiterated performances, but 'repeated acts within a highly rigid regulatory frame that congeal over time' so that they appear natural and constitute 'a political genealogy of gender ontologies'. This process is psychosocial, reiterating and creating identities as well as socioeconomic structures, but it is not as optional as Brubaker sometimes makes it seem since there are always 'highly rigid regulatory frames'. Equally, Brubaker's formulation sometimes renders the exclusionary processes (re)iterated in racialized identities silent because the history and contemporary enactments of racialization and racism are absent from his formulation. As a result, racialized identities seem deficient in being more essentialist than gendered identities.

Brubaker's formulation of race as an 'unsettled' and unsettling identity is unsatisfactory in paying insufficient attention to current theorisations of (racialized) identities. For example, it does not attend to internal differences between people in particular racialized categories. This matters because, as Brubaker recognizes, racialized 'border crossings' are more open to some than others in that the legacy of the 'onedrop rule' excludes those phenotypically legible as black, Asian, Arab etc., from inscription into whiteness.

Outside the domain of data collection, of course, options for meaningful and effective choice of racial and ethnic identity are unequally distributed. A dark-skinned person in the United States does not have a socially meaningful option to identify as white. (p. 54) 
Perhaps more important is the issue of what it means for categories to be socially constructed. What does it mean to be white in a context when the unmarkedness of whiteness makes it difficult for many white people to identify what constitutes whiteness other than skin colour. Difference within the category of blackness is also important in relation to the essentialism Brubaker discusses. From the 1990s onwards Paul Gilroy (e.g. 2000), amongst others, has explored the pervasiveness of 'ethnic absolutism' on both sides of the Atlantic. His critique makes clear that the internal policing of blackness is not absolute. Equally, scholars who explore 'post-race' positions do so from understandings of the relative genetic insignificance of race, the unsettled nature of racialized identities and the relevance of performativity and new ways of 'doing' blackness in different historical era (e.g. Ali, 2003; Nayak, 2006). They do not advocate those popular positions that suggest that 'race' no longer matters. Brett St Louis (2002: 653), for example, suggests that 'While there might be semantic mileage in the theoretical and analytical obsolescence of race, it remains a primary ascriptive marker of individual and group characteristics in the social world and also serves, at times, as a validation of discrimination and an incitement to violence'. Brubaker clearly recognizes this at various points in his essay. He says, for instance:

With the memory still fresh of the Charleston church massacre and the deaths that inspired the wave of Black Lives Matter protests, one needs no reminder of the analytical and political limits of a focus on passing and performance (p. 145).

However, his 'trying out' of ideas appears to render invisible the discrimination and violence associated with race, even though he mentions the 'Black Lives Matter' campaign.

Yet, in making his case, Brubaker sometimes leaves a gap between such sociostructural issues and the sometimes individualising rhetoric of notions of choice and self-transformation. For example, the paragraph following the one above suggests:

Still, the declining authority of ancestry over racial and ethnic classification...has substantially enlarged the space for choice, affiliation, and self-transformation. This holds even for a substantial and growing share of those whose ancestry, a few decades ago, would have unambiguously led them to classify themselves and to be classified by others, as black".

It would have been helpful to have these two paragraphs linked by more than the suggestion of simultaneity. This is particularly the case, since, as Brubaker recognizes, concern about separating 'mixed' categories from blackness were partly about the potential dilution of political power through the reduction of numbers in the 'black' category. While it is entirely reasonable that Brubaker does not conduct empirical research in this area or wait to do so before theorizing these issues, drawing on some of the empirical work done in related areas would have helped to deepen understanding of why the issues he addresses remain controversial. In this regard, it is instructive to consider Signithia Fordham's (2008) sustained attention to academically successful black young people in the US, what she calls their strategy of 'acting white' to generate success and the controversy with which such ideas have frequently been greeted. Similarly, Jefferson's (2016) memoir historicises socioeconomic and status divisions between African Americans.

A related point, and one to which Brubaker returns, is that part of the resistance to white people passing as black, Asian or First Nation is related to attempts to prevent cultural appropriation. This is undoubtedly, contentious for those who point out that, for example, white hip-hop artists are often more successful than black ones. Brubaker argues that crossover practices have come to be seen 'as potentially more affiliative than appropriative', subverting racial hierarchies rather than reinforcing them as deceptive and fraudulent. There are, of course, many instances where this is the case. However, the argument here would have been deepened by consideration of the now considerable work that has examined the contexts within which what is considered 'cultural appropriation' becomes acceptable and for whom. Early UK examples include work by Roger Hewitt (1986), Les Back (1996) and Phil Cohen (1997), but this issue has also been addressed 
in the US (e.g. Fordham, 2010). The lack of an intersectional approach also means that that the highly gendered nature of 'cultural appropriation' of, for example, hip-hop is omitted from discussion here.

In a text that he makes clear is 'exploratory, tentative, and incomplete', it may seem unfair to ask for more than Brubaker provides. However, by bringing these two concepts together, he encourages us to think even more broadly, about other boundaries and border crossings. What might be gained, for example, by considering 'trans' as in 'transnational' (migration or families). Perhaps the notion that people who move (countries) are both 'here and there' (Hondagneu-Sotelo and Avila, 1997), leave some behind as they forge new relations and are subject to the inextricable linking of relationality and national politics might have served to elucidate the relationality of positioning. It is true that Brubaker considers the 'trans' in 'transracial adoption'. However, he glosses over the numerous pieces of research published in this, and related areas, by suggesting that 'The Dolezal affair wrenched "transracial" out of the adoption context and brought it into conversation with "transgender"' and the new forms of 'unsettled identities' it produces ( $p$. 18). This misses a chance to think further about the complexity of 'transracial' and its commonalities with, and differences from 'transgender' as well as why various political and conceptual contestations persist despite the marked changes over time that Brubaker identifies (see, for example, Phoenix and Simmonds, 2012). As Lamont and Molnár (2002) suggested there is still a need for improved understanding of social and symbolic boundaries and the cultural mechanisms that produce them.

Despite the above critique, it is important to recognize that Brubaker's decision to interrogate the notion of 'trans' as used in 'transgender' and 'transracial' in the Caitlyn Jenner and Rachel Dolezal cases has, as he intended, been a tool to think 'with' rather than 'about' race, ethnicity, gender and their intersections. As such it is highly productive and stimulating. It will certainly encourage, and indeed provoke, novel reflection about 'the contingency and arbitrariness of racial categories, while remaining sensitive to the ways in which gender and race operate as different systems of embodied difference' (p. 151).

\section{References}

Ali, S.. 2003. Mixed-race, post-race: Gender, new ethnicities and cultural practices. Berg.

Butler, J. 1990. Gender trouble, feminist theory, and psychoanalytic discourse. Feminism/postmodernism.

Fordham, S. 2008. "Beyond capital high: On dual citizenship and the strange career of "acting white"." Anthropology \& Education Quarterly, 39(3), 227-246.

Fordham, S. 2010. "Passin' for Black: Race, identity, and bone memory in postracial America". Harvard Educational Review, 80(1), 4-30.

Foresight .2013. Future Identities: Changing Identities in the UK-The Next 10 Years. DR 3: Social Media and Identity.

Gilroy, P. 2000. Against race: Imagining political culture beyond the color line. Harvard University Press. Hondagneu-Sotelo, P. and Avila, E. 1997. "“I'm Here, but I'm There" the Meanings of Latina Transnational Motherhood." Gender \& Society, 11(5), 548-571.

Lamont, M. and Molnár, V. 2002 "The study of boundaries in the social sciences." Annual Review of Sociology, 167-195.

McCall, L. 2005. "The complexity of intersectionality." Signs, 30(3), 1771-1800.

Nayak, A. 2006. "After race: Ethnography, race and post-race theory". Ethnic and Racial Studies, 29(3), 411430. 
St Louis , B. 2002. "Post-race/post-politics? Activist-intellectualism and the reification of race." Ethnic and Racial Studies, 25:4, 652-675, DOI: 10.1080/01419870220136673

Wetherell, M. (ed.) 2009. Theorizing Identities and Social Action. Basingstoke: Palgrave Macmillan.

URL: http://mc.manuscriptcentral.com/rers ethnic@surrey.ac.uk 